This item was submitted to Loughborough's Research Repository by the author.

Items in Figshare are protected by copyright, with all rights reserved, unless otherwise indicated.

\title{
Underwater acoustic characterisation of unexploded ordnance disposal using deflagration
}

PLEASE CITE THE PUBLISHED VERSION

https://doi.org/10.1016/j.marpolbul.2020.111646

PUBLISHER

Elsevier

VERSION

AM (Accepted Manuscript)

\section{PUBLISHER STATEMENT}

This paper was accepted for publication in the journal Marine Pollution Bulletin and the definitive published version is available at https://doi.org/10.1016/j.marpolbul.2020.111646.

\section{LICENCE}

CC BY-NC-ND 4.0

\section{REPOSITORY RECORD}

Robinson, Stephen, Lian Wang, Sei-Him Cheong, Paul Lepper, Francesca Marubini, and John Hartley. 2020. "Underwater Acoustic Characterisation of Unexploded Ordnance Disposal Using Deflagration". Loughborough University. https://hdl.handle.net/2134/13379639.v1. 


\title{
Underwater acoustic characterisation of unexploded ordnance disposal using deflagration
}

\author{
Stephen P Robinson a, ${ }^{*}$, Lian Wanga , Sei-Him Cheonga, Paul A. Lepper ${ }^{b}$, Francesca Marubinic, John P Hartleyc \\ a National Physical Laboratory, Hampton Road, Teddington TW11 OLW, UK \\ ${ }^{b}$ Loughborough University, Loughborough LE11 3TU, UK \\ ${ }^{c}$ Hartley Anderson Ltd, Aberdeen, AB11 5BE, UK \\ * Corresponding author: Stephen P Robinson. Email address: stephen.robinson@npl.co.uk
}

\begin{tabular}{ll}
\hline ARTICLE INFO & ABSTRACT \\
\hline $\begin{array}{l}\text { Keywords: } \\
\text { UXO }\end{array}$ & The seabed off North West Europe contains much unexploded ordnance (UXO), posing a \\
acoustic & hazard to offshore developments such as windfarms. The typical removal method is \\
noise & through high-order detonation of a donor charge placed adjacent to the UXO. This method \\
pollution & poses a risk of injury or death to marine mammals and other fauna from the high sound \\
deflagration & levels produced. This paper describes a controlled field experiment to compare the sound \\
& produced by high-order detonations with a low-order disposal method called deflagration, \\
& which uses a shaped charge of modest size, is less energetic, and offers reduced \\
& environmental impact from lower acoustic output. The results demonstrate a substantial \\
& reduction over high order detonation, with the peak sound pressure level and sound \\
& exposure level being more than 20 dB lower for the deflagration, and with the acoustic \\
& output depending only on the size of the shaped charge (rather than the size of the UXO). \\
\hline
\end{tabular}

\section{Introduction}

Unexploded ordnance (UXO) litters the seabeds of European seas such as the North Sea, the Irish Sea and the Baltic, mainly as the result of past military conflicts, but also from military firing ranges, shipwrecks, and offshore munition disposal [Davies 1996, Eitner \& Tröster 2018, Albright 2012, Beddington and Kinloch 2005]. In some cases, the UXO can be avoided or safely removed. However, for some offshore developments, these pose a hazard and must be made safe.

In particular, the location and spatial scale of many offshore wind farm developments and cable connector projects means there is a high potential to encounter UXO during construction. This is particularly so where there is overlap with World War I and World War II conflict areas, military training areas and munitions disposal sites [Davies 1996, Eitner \& Tröster 2018; Detloff et al. 2012]. As part of development planning, detailed surveys are undertaken to identify possible UXO and confirm what action is needed to reduce health and safety risks to a tolerable level. When UXO cannot be avoided or safely removed, explosive ordnance disposal (EOD) is necessary. This typically involves detonation on site, and the favoured disposal method is to use a high-order detonation conducted by exploding a donor charge placed adjacent to the UXO munition [Albright 2012, Aker 2012, Sayle et al 2009, Cooper et al. 2018].

These disposals produce acoustic pulses, which can make significant contributions to the soundscape over a wide area [Sertlek et al. 2019, Merchant et al 2020], and can have a number of adverse environmental consequences, one of which is the risk to marine fauna from exposure to the high amplitude sound levels produced [von Benda-Beckmann et al. 2015; Yelverton et al. 1973; Dahl et al. 1996; Todd et al. 1996; Finneran et al. 2000, Ketten et al. 1993, Lewis 1996, Danil and St. Leger 2011, Brownlow et al 2015, Sundermeyer et al 2012, Parsons et al 2000].

Impulsive sounds of very high-amplitude also presents challenges for effective mitigation for compliance with regulations, with potentially large exceedance areas for commonly-used exposure thresholds [Southall et al. 2019; NMFS 2018; Finneran \& Jenkins 2012, Popper et al 2014]. Common mitigation strategies involve the use of spatial and temporal restrictions on the activity, passive acoustic monitoring, and the introduction of additional noise of lower amplitude to create an aversive reaction by use of Acoustic Deterrent Devices, and occasionally by use of small "scare" charges [JNCC 2010; Merchant \& Robinson 2020]. Noise abatement technologies have also been employed including the use of bubble curtains to attenuate the radiated sound [Merchant \& Robinson 2020; Loye \& Arndt 1948; Domenico 1982; 
Croci et al. 2014; Schmidtke 2010, Schmidtke 2012]. In recent years, there has been a focus on alternative methods of disposing of UXO [Koschinski 2011; Koschinski et al. 2009; Koschinski 2015] including the use of low-order techniques such as deflagration, a method that until recently has been more commonly used for military EOD operations [Merchant \& Robinson 2020; ESTCP 2002]. Deflagration consists of a process where the UXO shell is penetrated by a shaped charge with insufficient shock to detonate, and with the explosive material inside the UXO reacting with a rapid burning rather than a chain reaction that would lead to a full explosion [ESTCP 2002]. Deflagration is a much less energetic process and anecdotal evidence has suggested that it is "quieter" than traditional high-order detonation, but until now no acoustic measurements have been reported to support this conclusion.

This paper describes experimental work to compare the characteristics of the sound produced by deflagration with that of a traditional high-order detonation method [Cheong et al 2020]. Underwater explosions as sources of sound have been the subject of considerable scientific study since the 1940s, both theoretically and experimentally [Cole 1948; Arons 1954 and 1970; Weston 1960], including characterisation of explosive sources in shallow water environments [Gaspin et al 1972; Gaspin et al. 1979; Chapman 1985\&1988; Hannay \& Chapman 1999; Soloway \& Dahl 2014; Wiggins et al. 2019]. In an explosion, the chemical chain-reaction occurs at supersonic speed producing a high-amplitude pressure pulse which propagates nonlinearly in the form of a shock-wave which reaches out to a range of about $10^{5}$ times the charge radius [Cole 1948; Weston 1960]. Beyond this range, the propagation may be considered linear and use can be made of conventional linear propagation models and metrics such as source level [ISO 18405:2017].

In general, the sources in the previous studies have been suspended in the water column. The characterisation of UXO detonations presents additional difficulties because the condition of the ordnance itself can lead to a wide variation in the acoustic source level. The UXO will most likely be resting on the seabed and may be partially buried, and after perhaps 75 years in place may be substantially physically degraded [Cristaudo and Puleo 2020]. It is not possible to be certain of the effective charge size (and therefore the source level) for high-order detonations of UXO in real offshore environments because each individual UXO may be buried to a different degree on a different seabed type and with a different degree of physical degradation. This uncertainty makes it difficult to draw definitive conclusions about measurements made on UXO disposals in-situ.

Since the aim to the work reported here is to compare the acoustic output from high-order detonations with low-order deflagration, it was decided to conduct an experiment in a controlled environment to facilitate a "like-for-like" comparison. To this end, a field experiment was carried out in a flooded quarry where the environmental conditions, the quality of the munition, and the positioning of the source and acoustic instrumentation could be controlled [Cheong et al 2020].

The ordnance used for the experiment were specially-designed surrogate munitions such that each type used was identical (so variation through degradation was not an issue and the effective charge size would be known precisely), and the munitions were suspended at the same depth in the water column (so that proximity to the quarry floor was not an issue). Clearly, this experimental configuration is not similar to the situation in actual offshore EOD operations, but the simplifications allowed a true comparison to be made without extra uncertainties that exist in EOD operations offshore.

\section{Experimental method}

\subsection{Measurement configuration}

The measurement trial was undertaken in Limehillock Quarry, near Keith in the north of Scotland. The facility is used extensively for in-water shock testing of structures for offshore marine applications, and was operated by Thornton Tomasetti Defence Ltd (www.thorntontomasetti.com), who provided the logistical support for the trial.

The quarry is approximately $250 \mathrm{~m}$ long by $125 \mathrm{~m}$ wide, is a little over $20 \mathrm{~m}$ deep on average, and is filled with fresh water. The bathymetry between the position of the explosive source and that of the furthest hydrophone was $20.1 \mathrm{~m} \pm 1 \mathrm{~m}$. During the trial, the water temperature was stable at $10.5{ }^{\circ} \mathrm{C}$ for the shallowest $9 \mathrm{~m}$ of the water column, but the temperature declined to $6.1^{\circ} \mathrm{C}$ at the bottom.

The acoustic pulse from each explosive source were recorded at two measurement stations with sensors suspended from the water surface. These were: (i) close to the source (nominally $10 \mathrm{~m}$ and $20 \mathrm{~m}$ ); and (ii) at a distance of $147 \mathrm{~m}$ (at the far end of the quarry). The configuration is illustrated in Figure 1.

For the stations closer to the source, two types of underwater shock transducers were employed: T11 transducers (manufactured by Neptune Sonar, nominal charge sensitivity: $0.07 \mathrm{pC} / \mathrm{kPa}$; maximum pressure: $275 \mathrm{MPa}$ ) and 138A26 transducers (manufactured by 
PCB, nominal voltage sensitivity: $0.29 \mu \mathrm{V} / \mathrm{Pa}$; maximum pressure: $172 \mathrm{MPa}$ ). The shock transducers were powered by a PCB 482C05 four-channel unity-gain signal conditioner with additional PCB 422E06 charge amplifiers being used for the T11 transducers. A 16channel Yokogawa DL750 data recorder was used for capturing the data. All data were sampled at 500 kilosamples per second giving a time base resolution of $2 \mu \mathrm{s}$. The DL750 data acquisition system was triggered by a 'Charge Probe' which is fixed directly to the explosive and provided a voltage step at the time of detonation. The shock pressure sensors were suspended from floating pontoons and due to a slight re-positioning of the source between detonations, their separation distances varied between measurement sets. The distances were measured on the surface with a laser rangefinder (confirmed by the acoustic propagation delay) and ranged between $11.1 \mathrm{~m}$ and $12.9 \mathrm{~m}$ for the closer pair, and between $21.0 \mathrm{~m} 21.8 \mathrm{~m}$ for the other pair. All four sensors were deployed at $7 \mathrm{~m}$ water depth, the same depth chosen for all of the source charges.

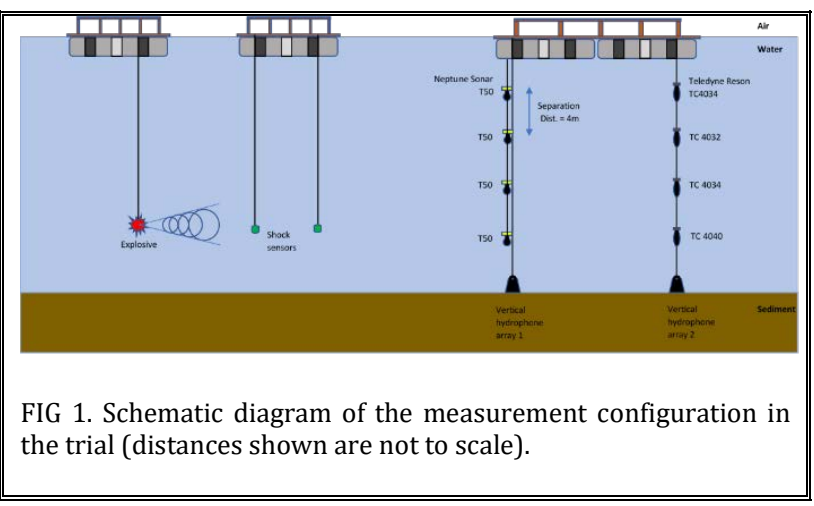

For the measurements made at $147 \mathrm{~m}$ from the source, two four-element hydrophone arrays were deployed from a tethered floating pontoon. The first array consisted of four T50 hydrophones (manufactured by Neptune Sonar, with nominal sensitivity $28 \mu \mathrm{V} / \mathrm{Pa}$ ), and the second array was made up by four hydrophones manufactured by Teledyne Reson, consisting of 2 x TC4034 ( $9 \mu \mathrm{V} / \mathrm{Pa})$, a TC4040 $(38 \mu \mathrm{V} / \mathrm{Pa})$, and a TC4032 $(6 \mathrm{mV} / \mathrm{Pa})$. Note that a number of insensitive hydrophones were used to measure the expected high amplitude pulses generated during the high-order detonations, but in addition hydrophones with a variety of sensitivities were used (including a highly sensitive TC4032) to cover the anticipated lower acoustic output from the deflagration. Except for the TC4032 (which has a built in preamplifier) the hydrophones were connected to high input impedance Teledyne Reson VP2000 amplifiers, and the acquisition was made using a PicoScope 4824 sampling at 1.25 mega-samples per second (time resolution of $0.8 \mu \mathrm{s}$ ), and two National Instrument USB 6363 DAQ cards sampling at 250 kilosamples per second (time resolution of $4 \mu \mathrm{s}$ ). All the hydrophone data were recorded by two different digitisers simultaneously providing some redundancy in order to avoid data loss by unexpected system failure. The trigger output from the DL750 used for the shock sensors was routed via a $200 \mathrm{~m}$ co-axial cable to the data acquisition system on the pontoon at $147 \mathrm{~m}$ in order to provide a common trigger and time-base between all data sets.

All hydrophones were calibrated traceable to national standards in the laboratory before the trial using the methods described in IEC 60565 [IEC 60565 $2019,2020]$, by comparison in a closed coupler in the range $5 \mathrm{~Hz}$ to $315 \mathrm{~Hz}$, and the free-field reciprocity method in the range $750 \mathrm{~Hz}$ to $20 \mathrm{kHz}$ for all hydrophones, with two hydrophones calibrated at frequencies up to $200 \mathrm{kHz}$. Before and after deployment, the hydrophone sensitivities were checked at $250 \mathrm{~Hz}$ using a portable calibrated pistonphone (this enabled a full system sensitivity check as recordings were made on the acquisition systems of signals of known sound pressure level).

\subsection{Preparation of explosive sources}

The aim in the choice of munitions was to use identical examples for both high-order and for deflagration, and to use an explosive constrained within steel containers to simulate a real UXO.

For this purpose, a number of "surrogate shells" were fabricated which consisted of steel cylinders containing either $10 \mathrm{~kg}$ or $5 \mathrm{~kg}$ of plastic explosive. The cylinders were of approximate diameter $200 \mathrm{~mm}$ and length $600 \mathrm{~mm}$ and had end caps secured with external bolts. The explosive filler was a plastic explosive (PE4) which consisted of $88 \%$ RDX plastic explosive (Grade 1 A), 11\% plasticiser and 1\% penta-erythritol dioleate. PE4 is a common and relatively insensitive handmouldable general-purpose plastic explosive which may be used underwater, and ignites at $218{ }^{\circ} \mathrm{C}$. The design, manufacture and operation of all the explosives was undertaken by staff of Alford Technologies Ltd (www.explosives.net).

For the high order tests, the surrogate shell was suspended from a float via $3 \mathrm{~mm}$ steel wires. The wires were measured to ensure that the charge was always at $7 \mathrm{~m}$ depth by taking into account how much of the float would be submerged under the weight of the charge and charge casing. For the deflagration tests, a large steel "catch-plate" was suspended in the water several metres beneath the charge to catch any unconsumed residue from the deflagration and prevent it from dropping to the quarry floor (and requiring 
retrieval after the test). The steel catch plate was suspended from a floating pontoon, with the charge float positioned in the centre of a moon-pool (an aperture in the pontoon which exposed the water surface). The catch plate was unnecessary for the highorder detonations where the explosive is consumed by the explosion with the products distributed throughout the water column.

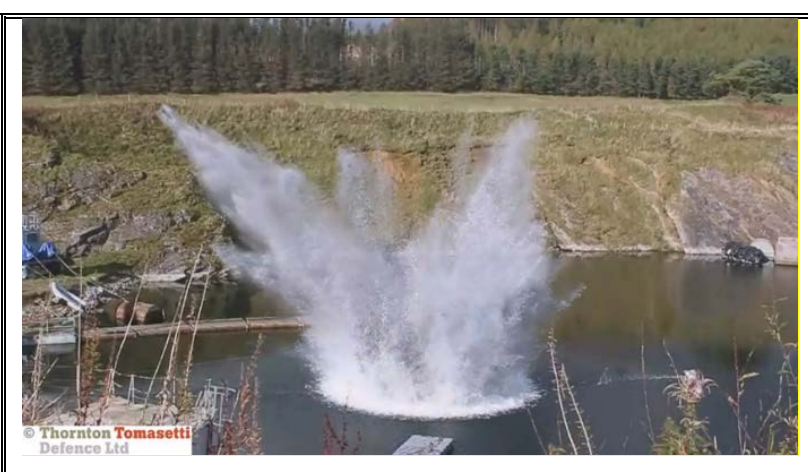

FIG 2. A $10 \mathrm{~kg}$ high-order detonation at the quarry site (courtesy of Thornton Tomasetti Defence Ltd).

A total of 17 charges were detonated during the trial. These consisted of four $10 \mathrm{~kg}$ shells and four 5 kg shells, with two of each size undergoing high-order detonation and two undergoing deflagration. Also, two other large charges were detonated by high-order: a $10 \mathrm{~kg}$ charge consisting of two $5 \mathrm{~kg}$ shells, and an $18.4 \mathrm{~kg}$ charge to dispose of explosive unused in the trial. In addition, detonations were carried out on a number of the shaped charges that were used in the deflagration process to determine the acoustic output of the shaped charges alone, and with the charge placed against a metal plate (the typical configuration when in use). The shaped charges were of size $15 \mathrm{~g}, 25 \mathrm{~g}, 48 \mathrm{~g}$ and $250 \mathrm{~g}$, this latter being the largest size of charge used in deflagration. Figure 2 shows a photograph of a $10 \mathrm{~kg}$ high order detonation.

\subsection{The deflagration method}

In general, ordnance is designed to be insensitive to mechanical and thermal impact, such as would occur from bullet or fragmentation impact. Thus, it is possible to penetrate UXO with a high velocity projectile and not cause any initial reaction. "Low-order" detonation tools or "disruptors" are designed to transmit enough reaction energy to the explosive charge so that the case ruptures, but not so much energy as to cause a full detonative chain reaction due to over-pressure. The definition of "low order" is "any explosive yield less than a full high-order" [Cooper 1996; ESTCP 2002]. With insufficient shock to detonate, the explosive material may instead react with a rapid burn, and this process is termed deflagration (essentially, vigorous burning with the reaction occurring at sub-sonic speeds). In the EOD community, it is taken to mean any process whereby a cased munition is caused to burn internally before bursting open, but without complete detonation of the contents.

The tool used for the work described here was a VULCAN ${ }^{\mathrm{TM}}$ shaped charge designed by Sydney Alford and manufactured by Alford Technologies [Patent W003/058155]. The shaped charge detonates and punches a small hole through the case of UXO, igniting and consuming the explosive fill which generates gas from the decomposition of the explosive. The accumulation of this gas causes the pressure to rise rapidly causing the UXO case to burst at the weakest point before a full detonation can occur, without instigating a high-order detonation. In contrast to the more commonly-used copper armour piercing shaped charge, when used for low order techniques the VULCAN $^{\mathrm{TM}}$ is fitted with a low-density incendiary projectile which forms a plasma jet which ignites as it forms. This provides a simple and reliable means of bringing about relatively gentle deflagration of small and large steel cased munitions with only a low probability of causing detonation.
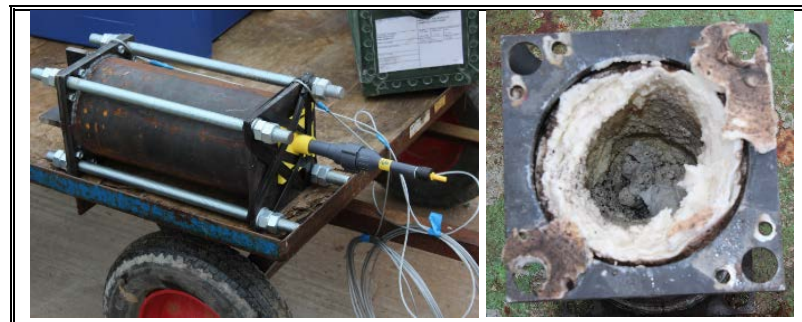

FIG 3. Left: a photograph of a $10 \mathrm{~kg}$ shell showing the $25 \mathrm{~g}$ shaped charge used to initiate deflagration. Right: a photograph of the shell and contents after deflagration (white and grey matter around inner edge of shell).

Figure 3 shows a photograph of a $10 \mathrm{~kg}$ surrogate shell showing the $25 \mathrm{~g}$ shaped charge used to initiate deflagration in position on the end cap. Also shown is a photograph of the shell after deflagration, showing that the central portion of the explosive had been consumed by the deflagration process, with residual explosive left around to outer rim (or escaping through the punctured casing).

For the high-order detonations of the shells, an explosive detonator was placed into the shell to initiate a high-order detonation directly. This ensured a full high-order detonation of shell contents so that a likefor-like comparison could be made, one of the objectives of this controlled study. If the experiment described here were attempted with as part of EOD 
operations at sea, the effective charge size would not always be known exactly because the donor charge may not detonate all of the munition.

\section{Results and discussion}

\subsection{Measurement results}

The recorded data for the acoustic pulses were analysed and two acoustic metrics were calculated: peak sound pressure in MPa (and its level in $\mathrm{dB}$ re 1 $\mu \mathrm{Pa})$; and the sound exposure level or SEL in $\mathrm{dB}$ re 1 $\mu \mathrm{Pa}^{2} \mathrm{~s}$. The focus was on these metrics because they are key to the calculation of exposure for marine fauna [Southall et al. 2019; NMFS 2018, Popper et al 2014]. The definitions of these terms were adopted from ISO 18405 [ISO 18405:2017], with the calculations on the acoustic pulse following the procedure described in NPL GPG133 [Robinson et al 2014] and ISO 18406 [18406:2017].

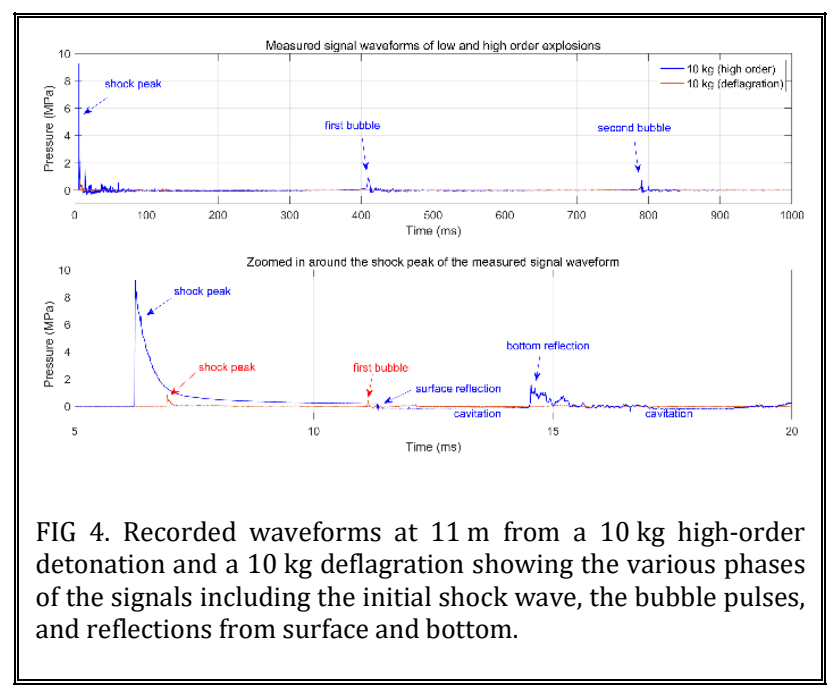

An example of the recorded time waveforms from the shock pressure sensors at $11 \mathrm{~m}$ is shown in Figure 4 for a high-order detonation of a $10 \mathrm{~kg}$ charge and a $10 \mathrm{~kg}$ deflagration. The upper plot shows a one second time window, which is sufficient to see the first and second bubble pulses caused by the explosion (generated as the bubble repeatedly expands and then collapses). The lower plot shows an expanded view of $15 \mathrm{~ms}$ around the shock peaks. The shock wave for the high-order detonation exhibits a very short rise time with a peak pressure of around $9 \mathrm{MPa}$ (a peak sound pressure level of $259 \mathrm{~dB}$ re $1 \mu \mathrm{Pa}$ ) whereas for the deflagration, the peak pressure is around $0.7 \mathrm{MPa}$. The exponential decay of the waveforms is interrupted by the surface reflection, after which some cavitation is evident (bubble formation caused when the shock wave reaches the water surface). The bottom reflection is also observed arriving at around $14 \mathrm{~ms}$.

Figure 5 shows the sound pressure power spectral density calculated from a waveform record length of 1 second for a high order detonation of a $5 \mathrm{~kg}$ charge measured at distances of $11 \mathrm{~m}$ and $21 \mathrm{~m}$. Each plot shows the spectra at each of the shock pressure transducers (two at each distance). Also shown are the spectra predicted by the model of Weston [Weston 1960] for the equivalent charge size. Ignoring the frequency domain interference due to reflected signals, the overall measured levels are close to those predicted by the model. The higher levels observed at frequencies above $10 \mathrm{kHz}$ are due to cavitation close to the water surface caused by the shock wave.

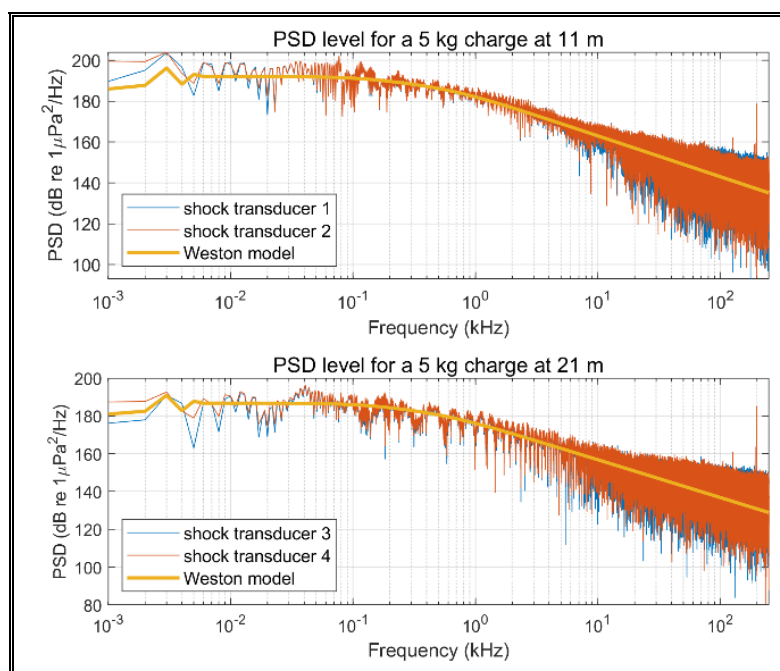

FIG 5. The sound pressure power spectral density for a high order detonation of a $5 \mathrm{~kg}$ charge at measured at $11 \mathrm{~m}$ and $21 \mathrm{~m}$, showing the measurements made by each of the four shock transducers and the predictions of the model by Weston.

The empirical models of Arons, Cole and Weston predict the peak pressure in the initial positivegoing shock wave as a function of scaled range as follows [Cole 1948; Arons 1954; Weston 1960]:

$$
p_{\mathrm{pk}}=K_{p}\left(\frac{R}{W^{1 / 3}}\right)^{\alpha}
$$

where $p_{\mathrm{pk}}$ is the peak pressure in $\mathrm{Pa}, R$ is the measurement range in metres, $W$ is the charge weight in kilograms of equivalent TNT, and $K_{p}$ and $\alpha$ are the shock and pressure coefficients, which are determined empirically (different authors report slightly different values for these constants). This equation was developed for TNT due to its historical use as a benchmark for energy from high explosives (a spherical TNT charge of density $1520 \mathrm{~kg} / \mathrm{m}^{3}$ is assumed). For other forms of explosive, the peak pressure can be predicted through use of explosivedependent coefficients that are used to scale $W$ to give a TNT-equivalent weight. A value of 1.3 has been used 
as the coefficient for the PE4 explosive used in this study (value obtained from Alford Technologies). Although originally formulated for spherical charges, the equation has been successfully employed for nonspherical charge geometries [Gaspin et al. 1979; Chapman 1985].

A key finding from the study is illustrated by Figure 6 which shows the peak sound pressure levels at distances of $11 \mathrm{~m}$ and $21 \mathrm{~m}$ plotted against charge size for all the detonations. The high-order detonations are clustered to the upper right of the plot, with the results of the shaped charges toward the bottom left (with lower charge sizes). The dotted lines represent fits to the data using the model of equation (1) which demonstrates that an empirical model of this type can be used to predict the peak sound pressure levels for all the charge sizes used. The model fit was undertaken using a two-parameter least-squares fit solving for values of the coefficients, with values of $\alpha$ equal to -1.31 and -1.27 for the $11 \mathrm{~m}$ and $21 \mathrm{~m}$ data respectively (obtained with RMS decibel errors of $0.73 \mathrm{~dB}$ and 0.55 $\mathrm{dB}$, and goodness of fit $\left(\mathrm{r}^{2}\right)$ estimates of 0.996 and 0.998).

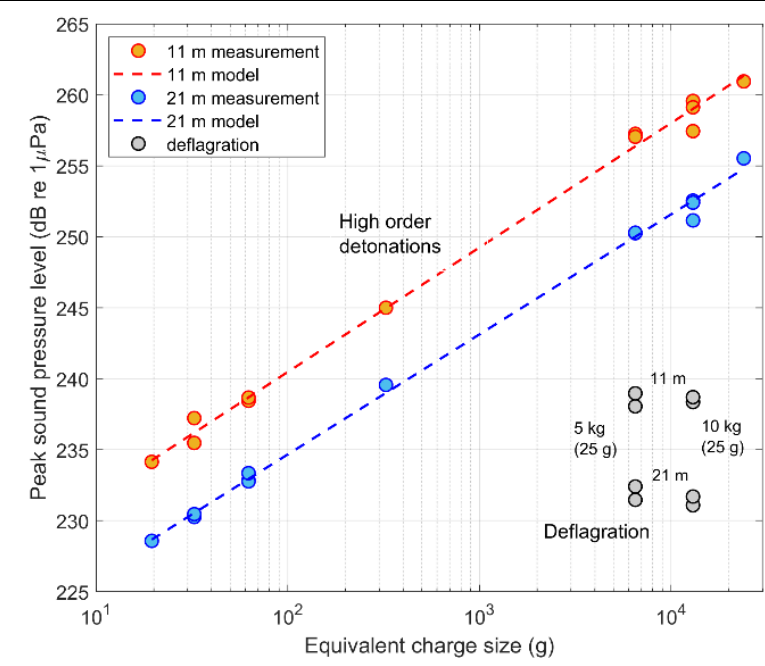

FIG 6. The peak sound pressure level at distances of $11 \mathrm{~m}$ and $21 \mathrm{~m}$ plotted against charge size for all the detonations. The dotted lines shows the prediction from the model of equation (1). The results of the deflagration are shown on the bottom right of the plot.

The results of the measurements of charges where deflagration was used are shown on the bottom right of the plot in grey symbols. This clearly shows a much lower level than for the high-order detonations for the same charge size, with a $>20 \mathrm{~dB}$ reduction in level (a factor of 10 reduction in peak sound pressure). For the $5 \mathrm{~kg}$ charge, a reduction in peak sound pressure levels of $20 \mathrm{~dB}$ and $21 \mathrm{~dB}$ are observed at $11 \mathrm{~m}$ and 21 $\mathrm{m}$ respectively.
The results obtained for the shaped charges of varying sizes show that the levels obtained for the deflagrations are very close to those for the equivalent size of shaped charges when detonated alone (either free or against a metal plate (an end cap from a surrogate munition).

Figure 7 shows the peak sound pressure level for all the measured charges from $11 \mathrm{~m}$ to $147 \mathrm{~m}$ plotted against scaled range $\left(R / W^{1 / 3}\right)$, which is the range divided by the cube root of the effective charge size. When plotted in this form, the data should follow an approximate straight line with a negative gradient. The plots shows the measured and predicted values from the model of Cole and Arons [Cole 1948; Arons 1954;], and that the measured data for all high-order detonations is close to the modelled values but is consistently slightly lower level. However, the peak sound pressure levels measured for low-order deflagrations (bottom left of the figure) are much reduced (by more than $20 \mathrm{~dB}$ ).

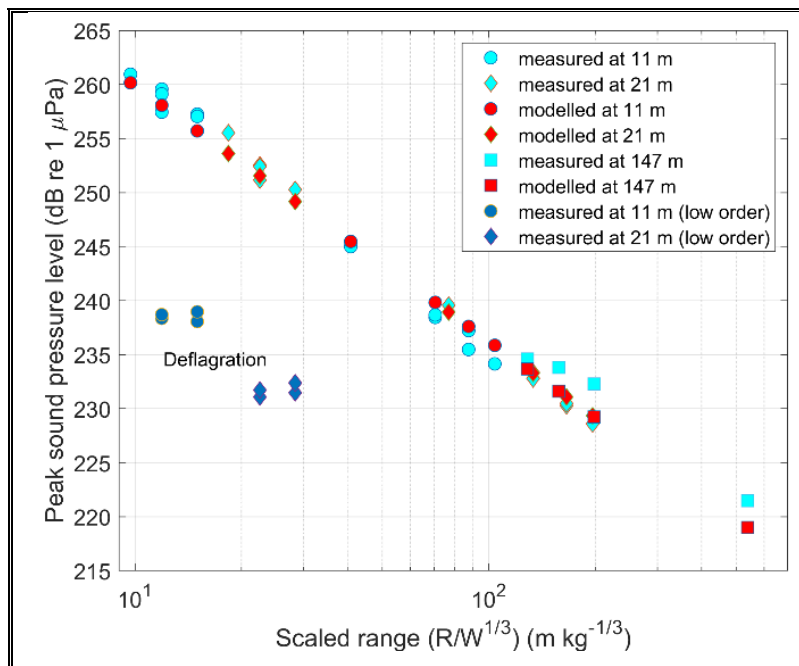

FIG 7. Peak sound pressure level for all the measured charges plotted against scaled range from $11 \mathrm{~m}$ to $147 \mathrm{~m}$, showing the measured data (blue) and predicted values (red). Again, the data for the deflagration (bottom left of the plot) is shown to be more than $20 \mathrm{~dB}$ lower.

The SEL, a metric commonly used in exposure calculations for marine fauna, is also substantially reduced when using deflagration. Figure 8 shows the SEL at nominal distances of both $11 \mathrm{~m}$ and $21 \mathrm{~m}$ calculated for a one second integration time plotted against charge size for all the detonations. The results of the measurements of charges where deflagration was used are shown on the bottom right of the plot. The data clearly show a much lower level than for the highorder detonations for the same charge size, with more than $20 \mathrm{~dB}$ reduction in SEL observed, equivalent to a factor of more than 100 in acoustic energy (for the $5 \mathrm{~kg}$ charge, a reduction in SEL of $23 \mathrm{~dB}$ and $21 \mathrm{~dB}$ are 
observed at $11 \mathrm{~m}$ and $21 \mathrm{~m}$ respectively, whereas for the $10 \mathrm{~kg}$ charge size, a reduction in SEL of $24 \mathrm{~dB}$ and $23 \mathrm{~dB}$ are observed at $11 \mathrm{~m}$ and $21 \mathrm{~m}$ respectively).

The empirical models established by Arons, Cole, and Weston [Cole 1948; Arons 1954; Weston 1960] may also be used to predict the sound exposure as a function of scaled range as follows:

$$
E=K_{E} W^{\frac{1}{3}}\left(\frac{W^{\frac{1}{3}}}{R}\right)^{\beta}
$$

where $E$ is the sound exposure in $\mathrm{Pa}^{2} \mathrm{~s}$, and $W$ and $R$ have the same meanings as for equation (1), and $K_{E}$ and $\beta$ are again determined empirically.

The dotted lines show the fit of the model which shows a different value of shock coefficient, $\beta$, for $11 \mathrm{~m}$ (a value of 1.49) than for $21 \mathrm{~m}$ (where the value is 1.36).

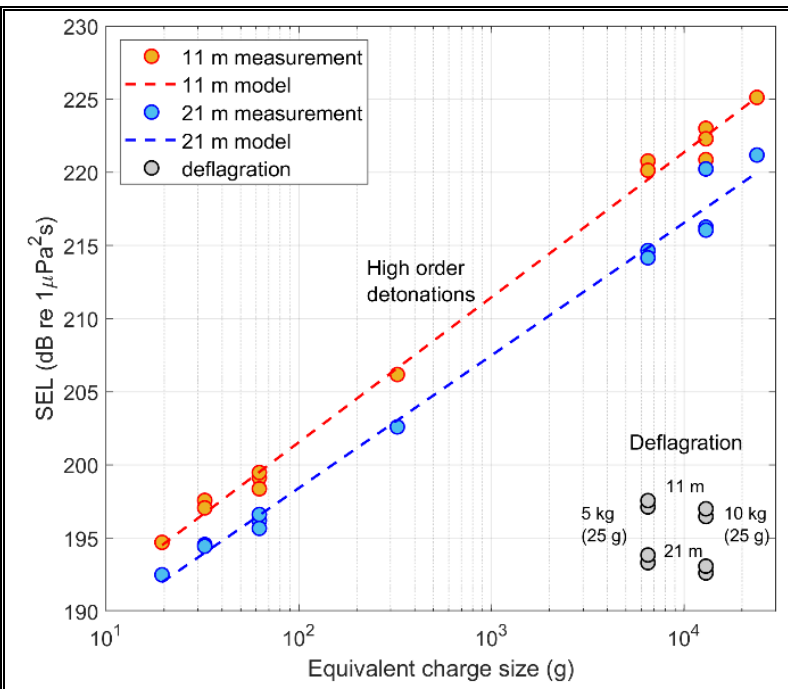

FIG 8. The SEL at a nominal distances of $11 \mathrm{~m}$ and $21 \mathrm{~m}$ plotted against charge size for all the detonations. The low-order deflagration data appear in the bottom right of the plot.

\subsection{Discussion}

The results of this study show that low-order deflagration offers a much lower amplitude of peak sound pressure than high-order detonations (by a factor of just over 10 in our trials). The peak sound pressure during deflagration appears to be due only to the size of the shaped charge used to initiate deflagration. This was in accord with the visual impression during the trial where the high-order detonations of a $10 \mathrm{~kg}$ shell caused a large airborne plume of water (see Figure 2), whereas the deflagration of the same size shell barely disturbed the surface of the water. One difference between the high-order detonations and the deflagration was the presence of the catch-plate for the deflagration. Since the levels measured for the deflagration were very similar to those of the shaped charges alone (with or without placement against a metal plate), it may be concluded that the catch plate did not significantly influence the radiated sound levels (though a small effect cannot be discounted).

Since the peak sound pressure levels scale with charge size (in agreement with existing model formulations), this enables the acoustic output to be predicted for deflagration as long as the size of the shaped charge is known. In addition, since the maximum size of shaped charge used for UXO deflagration is of the order of $250 \mathrm{~g}$, much greater reduction factors are feasible for very large UXO sizes (which can range up to several hundred kilograms). A reduction in peak sound pressure level from EOD operations is highly desirable for mitigation to reduce the source level from the UXO detonation, and to reduce the radius of impact zones over which the Permanent Threshold Shift and Temporary Threshold Shift thresholds are exceeded for exposure in the framework currently adopted by many regulators [Southall et al. 2019; NMFS 2018;].

The calculation of SEL is more challenging than the peak sound pressure level in the enclosed quarry because there are reflections from boundaries which arrive during the longer integration time used (one second). Estimating the peak sound pressure close to the source is not influenced by this because the shock front arrives first and any time window used to isolate it is very short. The time for the SEL calculation was kept long to include two pulses due to the gas bubbles produced by each explosion, and this inevitably includes reflections, for example from the water surface, and quarry bottom and side walls. This problem is likely to be worse for the measurements at greater distance from the source, and this is likely to contribute to the slightly poorer agreement with the model at $21 \mathrm{~m}$ compared to $11 \mathrm{~m}$, and the different value of shock coefficient obtained. The slightly higher SEL for smaller charges (15 g, $25 \mathrm{~g}$ and $48 \mathrm{~g}$ ) between the $11 \mathrm{~m}$ and $21 \mathrm{~m}$ giving rise to the differing fitted gradients is likely to be due to two factors. Firstly, the bottom reflection loss is reduced for $21 \mathrm{~m}$, and secondly, the relative contribution of surface reflection and cavitation effect will differ for the two ranges. The SEL at $11 \mathrm{~m}$ is dominated by the initial shock wave pulse, with much smaller contribution from the cavitation, but the shock wave is much lower at $21 \mathrm{~m}$, while the contribution from cavitation remains similar to that of at $11 \mathrm{~m}$, hence giving a higher relative cavitation contribution to the SEL at $21 \mathrm{~m}$.

The values of the shock coefficient calculated for the fitted models here differ slightly from the empirical fits reported in previous work where, for example, values of between -1.1 and -1.2 are typical for the value 
of $\alpha$ in equation (1) [Cole 1948; Arons 1954; Weston 1960]. This could be caused by a number of factors such as the experiment was conducted in fresh water rather than sea water (where properties such as absorption, sound speed and density are different), and because much of the previous work used direct detonation of spherical charges (whereas we are using a cylindrical shell to simulate a UXO). For the SEL calculation, the lack of an acoustic free-field due to the presence of reflected signals also influenced the SEL results (tending to cause an overestimate).

Using the Weston model (as plotted in Figure 7) it is possible to calculate either the peak sound pressure level or the SEL at any range within the "nonlinear" region where the shock wave propagates. Values for the two metrics for charge sizes where more than one example of high-order detonation was measured are shown in Table 1 for a nominal distance of $1 \mathrm{~m}$. Note that these do not represent source levels (for example, as defined in ISO 18405) which are defined in the far field for a linear monopole source.

\begin{tabular}{|c|c|c|c|}
\hline $\begin{array}{c}\text { Charge } \\
\text { size }(\mathrm{g})\end{array}$ & $\begin{array}{c}\text { Equivalent. } \\
\text { charge size } \\
(\mathrm{g}, \mathrm{TNT})\end{array}$ & $\begin{array}{c}\text { Peak sound } \\
\text { pressure level } \\
(\mathrm{dB} \text { re } 1 \mu \mathrm{Pa})\end{array}$ & $\begin{array}{c}\text { SEL } \\
(\mathrm{dB} \text { re } 1 \\
\left.\mu \mathrm{Pa}^{2} \mathrm{~s}\right)\end{array}$ \\
\hline 25 & 32.5 & 262 & 218 \\
\hline 48 & 62.4 & 265 & 221 \\
\hline 250 & 325 & 270 & 228 \\
\hline 5000 & 6500 & 280 & 242 \\
\hline 10000 & 13000 & 283 & 245 \\
\hline
\end{tabular}

Table 1. Estimates of peak sound pressure level and SEL for five charges for a nominal one metre range. Note that these do not represent linear monopole source levels.

Calculation of energy source levels is more problematic in the presence of reflected signals making these estimates somewhat less reliable. The values for the deflagration will be lower by the same $20 \mathrm{~dB}$ factor noted for the received peak sound pressure levels.

From a consideration of the acoustic output alone, this study has shown low-order deflagration to be an effective mitigation measure. However, other aspects need also consideration. For example, a feature of the deflagration method is that not all the explosive is consumed during the process. In this trial, for the two $10 \mathrm{~kg}$ charges that underwent deflagration, the weight of explosive consumed was $4.7 \mathrm{~kg}$ and $5.9 \mathrm{~kg}$ respectively, and for the two $5 \mathrm{~kg}$ charges it was $2.9 \mathrm{~kg}$ and $2.6 \mathrm{~kg}$. A UXO will typically burst or break open under the action of deflagration. It is undesirable to leave the explosive residue on the seabed because, while the risk of explosion has been removed, toxic chemicals may leak into the environment, an established risk with UXO degradation where toxins have been shown to accumulate in shell fish [Strehse $e t$ al 2017, Appel et al 2018, Maser et al 2020]. The remnants need to be collected, e.g. by ROV, as part of the complete EOD operation, including any small particulate matter. In the case of deflagration, the remnants are expected to be within close proximity to the UXO (within a few metres), which is why the use of the catch plate in the quarry was sufficient to capture the residue. However, the potential for chemical contamination from residues remains to be assessed.

Compared to high-order detonations, deflagration also offers the potential for reduced seabed destruction. The logistics, procedures, and costs are likely to be similar to those routinely used for highorder operations (with ROVs used for charge placement and/or residue collection). However, the techniques are not yet familiar within the civil offshore EOD community, regulators or developers and there is a need for a transfer of expertise, and technology to the wider community, and to transfer knowledge about the balance of risks to regulators and developers. There is a greater need to identify type of munition to ensure the success of deflagration, and not all UXO may be suitable candidates for the technique (for example, where degradation is too severe for identification). However, the technique is ready for trial in offshore EOD operations. The results of this study demonstrate a reduction in acoustic output when using the technique, enable predictions to be made of the likely acoustic output in the field, and will inform the choice of UXO disposal method (in balance with other considerations).

\section{Conclusions}

In this work, a controlled field experiment has been carried out to quantify the difference in acoustic output levels from two EOD methods. Results demonstrate that the deflagration method offers a substantial reduction in acoustic output over traditional high-order methods, with the peak sound pressure level and sound exposure level observed being typically more than $20 \mathrm{~dB}$ lower for the deflagration of the same sized munition (a reduction factor of just over 10 in peak sound pressure, and 100 in acoustic energy), and with the acoustic output depending on the size of the shaped charge (rather than the size of the UXO itself). Fits to semi-empirical equations for peak pressure and SEL, developed by earlier researchers, are shown to be consistent with these new results, enabling the prediction of the acoustic output levels from a variety of sizes of shaped charges. Compared to high-order methods, deflagration offers the potential for greatly reduced acoustic noise exposure of marine fauna and reduced destruction of the seabed. Offshore trials of the method will enable 
assessment to be made of the operational efficacy and the potential for any residual chemical contamination.

\section{CRediT authorship contribution statement}

Stephen P Robinson: Conceptualization, Methodology, Investigation, Writing - Original Draft. Paul A. Lepper: Conceptualization, Methodology, Investigation, Writing - Review \& Editing. Lian Wang: Formal analysis, Investigation, Methodology. Sei-Him Cheong: Software, Investigation, Methodology. Francesca Marubini: Conceptualization, Writing - Review \& Editing. John Hartley: Conceptualization, Writing Review \& Editing, Project administration.

\section{Declaration of interests}

The authors declare that they have no known competing financial interests or personal relationships that could have appeared to influence the work reported in this paper.

\section{Acknowledgements}

This project was funded by the UK's Department for Business, Energy and Industrial Strategy's Offshore Strategic Environmental Assessment programme (contract OESEA-19-107). The authors would like to acknowledge the contributions of the staff of Thornton Tomasetti during the controlled experiment (particularly Nick Misselbrook and Shaun Butcher), and of Alford Technologies for the design of the surrogate munitions and conducting the explosives operations, particularly Andy Carss.

\section{References}

Aker, J., Howard, B, and Reid, M. 2012. "Risk management for unexploded ordinance (UXO) in the marine environment", Dalhousie Journal of Interdisciplinary Management, 8. Available from: djim.management.dal.ca https://doi:10.5931/djim.v8i2.366

Albright R. D. 2012. Cleanup of Chemical and Explosive Munitions (Second Edition), Chapter 6 -Location, Identification and Environmental Remediation, 71-98, Elsevier, ISBN: 9781437734775. https://doi.org/10.1016/B978-1-43773477-5.00006-4

Appel, D., Strehse, J. S., Martin, H.-J., Maser, E., 2018. "Bioaccumulation of 2,4,6-trinitrotoluene (TNT) and its metabolites leaking from corroded munition in transplanted blue mussels (M. edulis)". Marine Pollution Bulletin 1351072 1078.

Arons, A. B. 1970. "Evolution of Explosion Pressure-Wave Characteristics in the Region Relatively Close to Origin," J. Acoust. Soc. Am. 47, 91.

Arons, A. B. 1954. "Underwater explosion shock wave parameters at large distances from the charge," J. Acoust. Soc. Am. 26, 343346.
Beddington J. and Kinloch A.J. 2005 Munitions dumped at sea: a literature review. Imperial College Consultants, London.

Brownlow, A. Baily, J, Dagleish, M. Deaville, R., Foster, G., Jensen, SK, Krupp, E., Law, R., Penrose, R., Perkins, M., Read, F., Jepson, $P ., 2015$. "Investigation into the long-finned pilot whale mass stranding event, Kyle of Durness, 2011", Report AC22/Inf.4.6.f $22^{\text {nd }}$ ASCOBANS Advisory Committee Meeting, The Hague, Netherlands, 29 September - 1 October 2015. Available from: https://www.ascobans.org/sites/default/files/document/A C22 Inf 4.6.f KyleOfDurness MSE.pdf

Cole R. H., 1948. Underwater Explosions Princeton University Press, Princeton, NJ.

Cooper P.W. 1996. Explosives Engineering. Wiley-VCH, ISBN 0471-18636-8,

Cooper, N. and Cooke, S. 2018. "Considerations for dealing with unexploded ordnance on maritime engineering projects", Proceedings of the Institution of Civil Engineers - Maritime Engineering, 171 (3), 121-131. ISSN 1741-7597 | E-ISSN 1751-7737

Chapman N. R., 1988. "Source levels of shallow explosive charges," J. Acoust. Soc. Am. 84, 697-702,

Chapman N. R., 1985. "Measurement of the waveform parameters of shallow explosive charges," J. Acoust. Soc. Am. 78, 672-681,

Cheong S-H, Wang L, Lepper P. A and Robinson S. P. "Characterisation of Acoustic Fields Generated by UXO Removal, Phase 2", Offshore Energy SEA Sub-Contract OESEA19-107, NPL Report AC 19, June 2020. Available from: https://assets.publishing.service.gov.uk/government/uploa ds/system/uploads/attachment data/file/893773/NPL 202 0 -

Characterisation of Acoustic Fields Generated by UXO Re moval.pdf

Costanzo, F. A. 2010. "Underwater Explosion Phenomena and shock physics," Proc. Of the IMAC-XXVIII, Florida, USA.

Cristaudo D. and Puleo J.A. 2020. "Observation of munitions migration and burial in the swash and breaker zones", Ocean Engineering, 205. https://doi.org/10.1016/j.oceaneng.2020.107322

Croci K., Arrigoni M., Boyce P., Gabillet C., Grandjean H.. 2014 "Mitigation of underwater explosion effects by bubble curtains : experiments and modelling". 23 ${ }^{\text {rd }}$ MABS (Military Aspects of Blast and Shock), Oxford, UK, Sep 2014, United Kingdom. 14p. https://hal.archives-ouvertes.fr/hal-01071652/

Dahl P. H., Jenkins A. K., Casper B., Kotecki S. E., Bowman V., Boerger C., Dall'Osto D. R., Babina M. A., and Popper A. N. 2020. "Physical effects of sound exposure from underwater explosions on Pacific sardines (Sardinops sagax)", J. Acoust. Soc. Am. 147 (4), 2383-2395.

Danil, K. and St. Leger, J.A., 2011. "Seabird and dolphin mortality associated with underwater detonation exercises". Mar. Technol. Soc. J. 45, 89-95. https://doi.org/10.4031/mtsj.45.6.5

Davies G. 1996. "Munitions dump explodes into headlines again", Marine Pollution Bulletin 32 (3), 250-251.

Detloff, K., Ludwichowski,I., Deimer, P., Schütte, H-J., Karlowski, U., Koschinski, S. 2012. "Environmental Nongovernmental Organizations' Perspective on Underwater Munitions", Mar. Technol. Soc. J., 46 (1), 11-16.

Domenico S. N.. 1982. "Acoustic wave propagation in air-bubble curtains in water-Part I: History and theory", GEOPHYSICS 47, 345-353,. https://doi.org/10.1190/1.1441340

ESTCP 2002. Report UX-0104, Low-Order Underwater Detonation, Environmental Security Technology Certification Program, U.S. Department of Defense. Available from: www.serdpestcp.org/download/file/MM-0104

Eitner J., and Tröster, S. 2018. "Hazardous contaminated sites in the North and the Baltic Sea", Research News RN08, 
Fraunhofer Institute for Chemical Technology, Munich Available from: $w w w . F r a u n h o f e r . d e$

Finneran, J. J., \& Jenkins, A. K. 2012. Criteria and thresholds for U.S. Navy acoustic and explosive effects analysis. San Diego, CA: SSC Pacific. https://doi.org/10.21236/ADA561707

Finneran, J. J., Schlundt, C. E., Carder, D. A., Clark, J. A., Young, J. A., Gaspin, J. B. 2000. "Auditory and behavioral responses of bottlenose dolphins (Tursiops truncatus) and white whales (Delphinapterus leucas) to impulsive sounds resembling distant signatures of underwater explosions". J. Acoust. Soc. Am., 108, 417-431.

Hannay B. and Chapman N.R. 1999. "Source levels for shallow underwater sound charges", J. Acoust. Soc. Am. 105 (1), 260263.

Gaspin J. B., Goertner J. A., and Blatstein I. M. 1979. "The determination of acoustic source levels for shallow underwater explosions," J. Acoust. Soc. Am. 66, 1453-1462.

Gaspin, J. B. and Shuler V. K. 1972. "Source Levels of Shallow Underwater Explosions", J. Acoust. Soc. Am. 51, 1202 https://doi:10.1121/1.1912961

IEC 60565-1:2020 Underwater acoustics - Hydrophones Calibration of hydrophones - Part 1: Procedures for free-field calibration of hydrophones, International Electrotechnical Commission, Geneva, Switzerland.

IEC 60565-2:2019 Underwater acoustics - Hydrophones Calibration of hydrophones -Part 2: Procedures for low frequency pressure calibration, International Electrotechnical Commission, Geneva, Switzerland.

ISO 18405:2017 Underwater Acoustics - Terminology, ISO (the International Organization for Standardization), Switzerland, 2017.

ISO 18406:2017, Underwater Acoustics - Measurement of Radiated Underwater Sound from Percussive Pile Driving, ISO (the International Organization for Standardization), Switzerland, 2017.

JNCC 2010. JNCC guidelines for minimising the risk of injury to marine mammals from using explosives (August 2010).

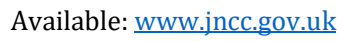

Ketten, D.R., Lien, J., Todd, S. 1993. "Blast injury in humpback whale ears: evidence and Implications". J. Acoust. Soc. Am. 94 1849-1850. https://doi.org/10.1121/1.407688

Koschinski, S. and Kock, K. H., 2015. "Underwater Unexploded Ordnance - Methods for a Cetacean-friendly Removal of Explosives as Alternatives to Blasting", 22 ${ }^{\text {nd }}$ ASCOBANS Advisory Committee Meeting.

Koschinski, S. 2011. "Underwater noise pollution from munitions clearance and disposal, possible effects on marine vertebrates, and its mitigation" Mar. Technol. Soc. J., 45 (6), 80-88.

Koschinski, S. and Kock, K. H.” 2009. "Underwater Unexploded Ordnance - Methods for a Cetacean-friendly Removal of Explosives as Alternatives to Blasting", Reports Int. Whal. Comm. SC/61 E. https://literatur.thuenen.de/digbib extern/dk041983.pdf

Lewis, J.A., 1996. "Effects of Underwater Explosions on Life in the Sea". Defence Science and Technology Organization, Canberra, Australia https://apps.dtic.mil/dtic/tr/fulltext/u2/a315490.pdf

Loye D.P. and Arndt W.F. 1948. "A sheet of ar bubble as an acoustic screen for underwater noise", J. Acoust. Soc. Am. 20 (2), 143145.

Maser, E., Strehse, J. S. 2020. "Don't Blast: blast-in-place (BiP) operations of dumped World War munitions in the oceans significantly increase hazards to the environment and the human seafood consumer". Archives of Toxicology 13

Merchant N. D., Andersson, M. H, Box, T., Le Courtois, F., Cronin, D. Holdsworth. N., Kinneging, N. Mendes, S., Merck, T., Mouat, J., Norro, A. M. J., Ollivier, B., Pinto, C., Stamp, P. and Tougaard, J.
2020. "Impulsive noise pollution in the Northeast Atlantic: Reported activity during 2015-2017", Marine Pollution Bulletin, 152.

https://doi.org/10.1016/i.marpolbul.2020.110951

Merchant, N.D., Robinson, S.P. 2020. "Abatement of underwater noise pollution from pile-driving and explosions in UK waters". Report of the UKAN Noise Abatement Workshop, 12 November 2019 at The Royal Society, London. https://doi:10.6084/m9.figshare.11815449

NMFS 2018. "Revisions to Technical Guidance for Assessing the Effects of Anthropogenic Sound on Marine Mammal Hearing", NOAA Technical Memorandum NMFS-OPR- 59, 167p, US Dept. of Commer., NOAA.

Robinson, S.P., Lepper, P. A. and Hazelwood, R.A., "Good Practice for Underwater Noise Measurement", NPL Good Practice Guide No. 133, National Measurement Office, Marine Scotland, The Crown Estate, ISSN: 1368-6550. Available from: www.npl.co.uk/acoustics

Parsons E.C.M., Birks I., Evans P.G.H., Gordon J.C.D., Shrimpton J.H. and Pooley S. 2000. "The possible impacts of military activity on cetaceans in west Scotland", European Research on Cetaceans, 14, 185 - 190.

Patent WO 03/058155 A1, 2003. International patent "Device for disruption of explosive ordnance", 17 July 2003.

Popper, A.N., Hawkins, A.D., Fay, R.R., Mann, D.A., Bartol, S., Carlson, T.J., Coombs, S., Ellison, W.T., Gentry, R.L., Halvorsen, M.B., Løkkeborg, S., Rogers, P.H., Southall, B.L., Zeddies, D.G., Tavolga, W.N. 2014. "Sound Exposure Guidelines for Fishes and Sea Turtles: A Technical Report” ASA S3/SC1.4 TR-2014, ANSI Accredited Standards Committee S3/SC1, American National Standards Institute, 2014 https://doi.org/10.1007/978-3-319-06659-2

Sayle, S., Windeyer, T. C. M., Conrod, S. Stephenson, M. 2009. "Site Assessment and Risk Management Framework for Underwater Munitions". Marine Technology Society Journal, 43 (4), 41-51. https://doi.org/10.4031/MTSJ.43.4.10

Sertlek H. O., Slabbekoorn H., ten Cate C. and Ainslie M. A. 2019. "Source specific sound mapping: Spatial, temporal and spectral distribution of sound in the Dutch North Sea", Environmental Pollution, 247, 1143-1157.

Schmidtke, E. B. "Schockwellendämpfung mit einem Luftblasenschleier zum Schutz der Meeressäuger", (Shock wave damping with an air bubble curtain to protect marine mammals), Proceedings of DAGA 2010, p. 689-690, Berlin, March

2010. http://pub.degaakustik.de/DAGA 2010/data/articles/0001 40.pdf

Schmidtke, E. B. "Schockwellend"ampfung mit einem Luftblasenschleier im Flachwasser", (Shock wave damping with an air bubble curtain in shallow water), Proceedings of DAGA 2012, p. 949-950, Darmstadt, March 2012 http://pub.degaakustik.de/DAGA 2012/data/articles/0003 32. pdf

Soloway A. G. and Dahl P. H. 2014. "Peak sound pressure and sound exposure level from underwater explosions in shallow water", J. Acoust. Soc. Am. 136 (3), El218-223.

Southall B.L., Finneran, J. J., Reichmuth, C., Nachtigall, P.E., Ketten, D.R., Bowles, A.E., Ellison, W.T., Nowacek, D.P., and Tyack, P.L. 2019. "Marine Mammal Noise Exposure Criteria: Updated Scientific Recommendations for Residual Hearing Effects", Aquatic Mammals, $45 \quad$ (2), 125-232. https://doi:10.1578/AM.45.2.2019.125

Strehse, J. S., Appel, D., Geist, C., Martin, H.-J., Maser, E., 2017. "Biomonitoring of 2,4,6-trinitrotoluene and degradation products in the marine environment with transplanted blue mussels (M. edulis)". Toxicology 390, 117-123.

Sundermeyer J.K., Lucke K., Dähne M., Gallus A., Krügel K., Siebert U. 2012. "Effects of Underwater Explosions on Presence and Habitat Use of Harbor Porpoises in the German Baltic Sea". In: 
Popper A.N., Hawkins A. (editors), The Effects of Noise on Aquatic Life. Advances in Experimental Medicine and Biology, 730. Springer, New York, NY. https://doi.org/10.1007/9781-4419-7311-5 64

Todd, S., Stevick, P., Lien, J., Marques, F., \& Ketten, D. 1996. "Behavioral effects of exposure to underwater explosions in humpback whales (Megaptera novaeangliae)", Canadian Journal of Zoology, 74, 1661-1672.

von Benda-Beckmann A. M., Aarts G., Sertlek H. O., Lucke K., Verboom W. C., Kastelein, R. A., Ketten D. R., van Bemmelen R., Lam F. A., Kirkwood R. J. and Ainslie M. A. 2015. “Assessing the Impact of Underwater Clearance of Unexploded Ordnance on Harbour Porpoises (Phocoena phocoena) in the Southern North Sea", Aquatic Mammals, 41 (4), 503-523.

Weston D. 1960. "Underwater explosions as acoustic sources". Proc. Phys. Soc. 76, 233-249.

Yelverton, J. T., Richmond, D. R., Fletcher, E. R., Jones, R. K. 1973. "Safe distances from underwater explosions for mammals and birds", Lovelace Foundation for Medical Education and Research, Albuquerque NM 87108, AD-766 952. 